\title{
Building a database for energy sufficiency policies [version 1;
}

\section{peer review: 2 approved]}

\section{Benjamin Best (D1, Johannes Thema (D1), Carina Zell-Ziegler (D2)3, Frauke Wiese (iD), Jonathan Barth5, Stephan Breidenbach6, Leonardo Nascimento7,8, Henry Wilke 6}

\author{
${ }^{1}$ Wuppertal Institut für Klima, Umwelt, Energie gGmbH, Döppersberg 19, Wuppertal, D-42103, Germany \\ 2Öko-Institut e.V., Büro Berlin, Borkumstraße 2, Berlin, D-13189, Germany \\ ${ }^{3}$ Technische Universität Berlin, Straße des 17. Juni 135, Berlin, D-10623, Germany \\ ${ }^{4}$ Europa-Universität Flensburg, Auf dem Campus 1, Flensburg, D-24943, Germany \\ ${ }^{5}$ ZOE. Institute for future-fit economies gUG, Norbertstr. 31, Cologne, D-50670, Germany \\ ${ }^{6}$ GermanZero e.V., Geschäftsstelle Berlin, Franklinstraße 27, Berlin, D-10587, Germany \\ ${ }^{7}$ NewClimate Institute, Waidmarkt 11a, Cologne, D-50676, Germany \\ 8 Wageningen University and Research, P.O. Box 9101, Wageningen, 6700 HB, The Netherlands
}

V1 First published: 24 Feb 2022, 11:229

https://doi.org/10.12688/f1000research.108822.1

Latest published: $04 \mathrm{Jul} 2022,11: 229$

https://doi.org/10.12688/f1000research.108822.2

\section{Abstract}

Sufficiency measures are potentially decisive for the decarbonisation of energy systems but rarely considered in energy policy and modelling. Just as efficiency and renewable energies, the diffusion of demand-side solutions to climate change also relies on policy-making. Our extensive literature review of European and national sufficiency policies fills a gap in existing databases. We present almost 300 policy instruments clustered into relevant categories and publish them as "Energy Sufficiency Policy Database". This paper provides a description of the data clustering, the set-up of the database and an analysis of the policy instruments. A key insight is that sufficiency policy includes much more than bans of products or information tools leaving the responsibility to individuals. It is a comprehensive instrument mix of all policy types, not only enabling sufficiency action, but also reducing currently existing barriers. A policy database can serve as a good starting point for policy recommendations and modelling, further research is needed on barriers and demandreduction potentials of sufficiency policy instruments.

\section{Keywords}

energy demand, sufficiency policy, behavioural change, energy descent, socio-ecological transformation, policy database

\section{Open Peer Review}

Approval Status

1

version 2

(revision)

04 Jul 2022

version 1

24 Feb 2022

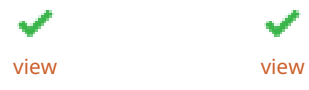

1. Gibran Vita, Open University of the

Netherlands, Heerlen, The Netherlands

2. Mirko Schäfer (iD), University of Freiburg,

Freiburg, Germany

Celia Burghardt, INATECH, University of Freiburg, Freiberg, Germany

Any reports and responses or comments on the article can be found at the end of the article. 


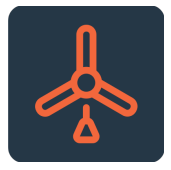

This article is included in the Energy gateway.

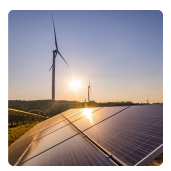

This article is included in the Energy Systems

Modelling collection.

Corresponding author: Benjamin Best (benjamin.best@wupperinst.org)

Author roles: Best B: Conceptualization, Funding Acquisition, Investigation, Methodology, Project Administration, Writing - Original Draft Preparation, Writing - Review \& Editing; Thema J: Conceptualization, Formal Analysis, Investigation, Methodology, Visualization, Writing - Original Draft Preparation, Writing - Review \& Editing; Zell-Ziegler C: Conceptualization, Formal Analysis, Investigation, Methodology, Writing - Original Draft Preparation, Writing - Review \& Editing; Wiese F: Conceptualization, Funding Acquisition, Investigation, Methodology, Project Administration, Resources, Writing - Original Draft Preparation, Writing - Review \& Editing; Barth J: Resources; Breidenbach S: Resources; Nascimento L: Resources, Writing - Review \& Editing; Wilke H: Resources

Competing interests: No competing interests were disclosed.

Grant information: The Federal Ministry of Education and Research (BMBF) is funding the project "EnSu - Energy Sufficiency in Energy Transition and Society" within the framework of the Strategy "Research for Sustainability" (FONA) www.fona.de/en as part of its SocialEcological Research funding priority, funding nos. [01UU2004A, 01UU2004B, 01UU2004C]. Responsibility for the content of this publication lies with the authors.

The funders had no role in study design, data collection and analysis, decision to publish, or preparation of the manuscript.

Copyright: ( $\odot 2022$ Best B et al. This is an open access article distributed under the terms of the Creative Commons Attribution License, which permits unrestricted use, distribution, and reproduction in any medium, provided the original work is properly cited.

How to cite this article: Best B, Thema J, Zell-Ziegler C et al. Building a database for energy sufficiency policies [version 1; peer review: 2 approved] F1000Research 2022, 11:229 https://doi.org/10.12688/f1000research.108822.1

First published: 24 Feb 2022, 11:229 https://doi.org/10.12688/f1000research.108822.1 


\section{Introduction}

Sufficiency is a potentially low-cost, fast and socially just mean of global greenhouse gas (GHG) mitigation. It is linked to multiple benefits for human well-being. ${ }^{1}$ The understanding of sufficiency varies across disciplines and discursive spheres; in relation to energy, sufficiency is the strategy that aims at achieving absolute reductions in the use of energybased services. ${ }^{2}$ Energy sufficiency, renewable energies and energy efficiency are all methods to reduce emissions associated with energy use. Renewables substitute fossil fuels, efficiency means finding ways to reduce losses by improving the input/output relation, and sufficiency equals avoiding/shifting energy services altogether.

Just as renewable energy and efficiency technologies, energy sufficiency is enabled and promoted by policy action. It is a genuine field of policy making, a case for regulatory frameworks and infrastructures, much beyond micro-level individual behaviour changes. ${ }^{1,3-6}$ We differentiate three sufficiency types to categorise policy instruments by whether they are aimed at a clear avoid strategy, i.e. a reduction of services; at shift, i.e. substituting energy intensive practices by less energy-intensive ones; or in general supporting reductions and substitutions. ${ }^{[1]}$

\section{Information gap: a sufficiency policy database}

The need for a sufficiency policy database has been formulated by various researchers and ministerial representatives, e.g. Toulouse et al. ${ }^{7}$ and Zell-Ziegler and Förster. ${ }^{8}$ Sufficiency is underrepresented in climate change mitigation policy and energy and climate scenarios so far (e.g. Samadi et al. $\left.{ }^{9}\right)$. A database on energy sufficiency could serve as a starting point for the collection of policy instruments, their assessment in a structured format, as precondition for further research and policy consulting and to complement the discussion on mitigation policy options.

Such database should provide information on good practices, implementation examples and insights on emission and energy reduction potentials. An openly accessible database can collect findings, ideas and examples and make them better accessible to policy makers than'hidden' in e.g. a project report.

When consulting existing climate end energy policy databases, for example International Energy Agency's (IEA) Policy Database ${ }^{10}$ and European Environment Agency's (EEA) Database on Greenhouse Gas Policies and Measures in Europe, ${ }^{11}$ it is striking that demand-side solutions to climate change and especially sufficiency options are underrepresented. Many sufficiency-minded bottom-up initiatives are included in the database on Transformative Social Innovations ${ }^{12}$ hosted by Dutch Research Institute For Transition (DRIFT), but this database does not focus on policy instruments. The NewClimate Institute's Climate Policy Database ${ }^{13}$ and the Mesures d'Utilisation Rationnelle de l'Energie (MURE) database on energy efficiency measures ${ }^{14}$ include sufficiency and/or the reduction of energy service demand in their search masks. However, the scope of these databases is different to our purpose: the Database of NewClimate aims at tracking climate action worldwide and thus focuses on mitigation plans and decarbonisation roadmaps rather than on specific policy instruments. The MURE database explicitly considers sufficiency policies and indicators since spring $2021,{ }^{15}$ including detailed descriptions and quantification, but only for policies that are already implemented, which limits the openness for new proposals. Another database is the Policy Ideas Database for Sustainable Prosperity from the Institute for Future-Fit Economies (ZOE). ${ }^{16}$ The ZOE-database is not a classical database, but a narrative and graphical visualisation, however, it is a valuable source for visionary cross-sectoral policies.

\section{Methods}

This section briefly describes the structure of the database, starting with sources for entries. To improve accessibility, and to allow for filtering, clustering and potential further analyses, we propose a number of structuring categorisations including information on sectors, goals, target indicators, policy instruments and sufficiency types. Moreover, we outline our internal review and harmonisation process and the technical setup of the database.

\section{Data sources}

Policy instruments are mainly extracted from existing literature and databases using the classifying parameters outlined below. Two key sources are first an extensive and detailed report describing policy measures for a "German Zero" emissions scenario until $2035^{17}$ and second a list of policy measures extracted from all European National Energy and Climate Plans (NECPs) published by Zell-Ziegler et $a .^{2}$ and condensed to merge instruments described by various NECPs. This is complemented by databases such as the Sustainable Prosperity Database ${ }^{16}$ and by further literature ${ }^{18-30}$ as well as exchange with experts. For a full list of references, see the respective tab in the database (please see underlying data). ${ }^{31}$

${ }^{1}$ For more details and examples see Zell-Ziegler et $a l^{2}$ 
Build-up of database - structuring the data

To allow for the analysis of policy instruments, we structured the database along several key categories:

Sector includes information on the covered sector: agri-food, buildings, industry/production, transport, LULUCF (land use, land-use change and forestry), energy and cross-sectoral (for overarching policies targeting various sectors).

Goal/policy strategy describes what the respective policy aims at, while

Measure/action explains the more concrete changes envisaged to achieve the policy goals and the mitigation target.

Indicator lists quantifiable units to be used to estimate the effect of the policy instrument/policy.

Sufficiency type categorises instruments according to the strategies avoid, shift or generally supporting.

Policy instrument lists the specific policy instrument from the respective source that is intended to lead to change and the description gives more details on the specifications of the instrument.

Instrument type categorises the policy instrument types according to UNFCCC categories, ${ }^{32}$ adding one for "not specified", where actions are listed in sources but respective instruments are not specified.

References are included with a link and page reference to facilitate retrieval of original sources.

The latest version of the database is available under https://energysufficiency.de/policy-database/.

As the database will be further developed, additional categories may be included such as push/pull measures, ${ }^{33}$ governance levels at which they are implemented in a multi-level governance system, ${ }^{34,35}$ policy interactions, and whether they constitute a sufficiency promotion or reduction of barriers.

Internal review

In order to increase consistency and interrater reliability of the database and to avoid duplicate entries, the data collection and cleaning process was organised with multiple internal review loops:

- Assignation of main sector responsible to each sector (out of the four first authors)

- Initial policy collection by main sector responsible

- Assignation of reviewer to each sector (out of the four first authors), review of all entries including: clarity of entries, correct coding, plausible entries (esp. goal/policy strategy, measure/action, indicator, instrument type)

- Bilateral coder meetings for clearance of divergences where necessary

- Loops of coder-meetings to sort out inconsistencies and establish a common understanding and coding procedure

- Where multiple policy instruments were listed, prioritisation on main instrument or splitting of policy in respective separate instruments (rows)

- Harmonisation of goals and indicators within and across sectors

Build-up of database

The database needs to meet the following requirements in order to be of highest utility and used most efficiently:

- Online availability with open access

- Clear design and easy navigation through the dataset

- Possibility to filter and search for keywords 
- Possibility to insert additional information on policies (description as floating text)

- Possibility to include attachments (e.g. sufficiency policy impact chains, planned to be developed)

- Possibility to download the data

Furthermore, the possibility to propose new policies and an integrated feature for a review process is desirable.

In order to find a software solution that may deliver on these aspects we exchanged with the hosts of comparable policy databases and with persons from our networks and a person from the EnSu project's advisory board ${ }^{[2]}$.

\section{Results}

The database version published with this article contains 281 policies from seven sectors (Figure 1 shows freight transport separately). One third of these are from the transport sector, followed by 62 policies in the building sector and 48 crosssectoral measures that address more than one sector. Some provide indirect connections with sufficiency measures such as reductions of subsidies for fossil fuels. The sources we analysed contained only very few sufficiency measures for the LULUCF (4) and energy (6) sector. The sufficiency measures in the energy sector concentrate on the overall policy goal 'reduce energy consumption' with such instruments as e.g. 'subsidise energy savings'. ${ }^{28}$

We include modal shift measures in the transport sector, labeled as sufficiency type shifting from high-energy to lowerenergy modes (shift). Of the 95 transport entries, 56\% aim at mode shift from cars to public transport and active modes (walking, cycling) (see Figure 2). In the transport sector, shift policies dominate, indicating that this is a key policy strategy for transport. Somewhat less common is the reduction of necessary trips and thus traffic (avoid), e. g. through support of teleworking or city planning to reduce distances between points of interest. Shift policies also dominate in the industry and agri-food domain.

In the building sector, sufficiency instruments of the 'avoid' type dominate in our database so far, aiming at an efficient use of living space and development of the existing building stock, focusing on quality of living and by that reduce overall living space and required land sealing. In the industry/production sector, avoid measures target at enhancing product lifetimes by increasing reparability and durability.

The database includes existing and proposed policy instruments of all types as categorised by UNFCCC. ${ }^{32}$ Most of the policy instruments in the database are of regulatory nature (108), economic (45, e.g. taxation) or fiscal (66, e.g. infrastructural or subsidies) (see Figure 3). The high share of regulatory instruments is in contrast to sufficiency policy instruments that are implemented or planned by EU member states, as listed in $\mathrm{NECPs}^{2}$ where regulatory instruments are underrepresented. The diversity of instrument types shows that sufficiency policies are not only information campaigns

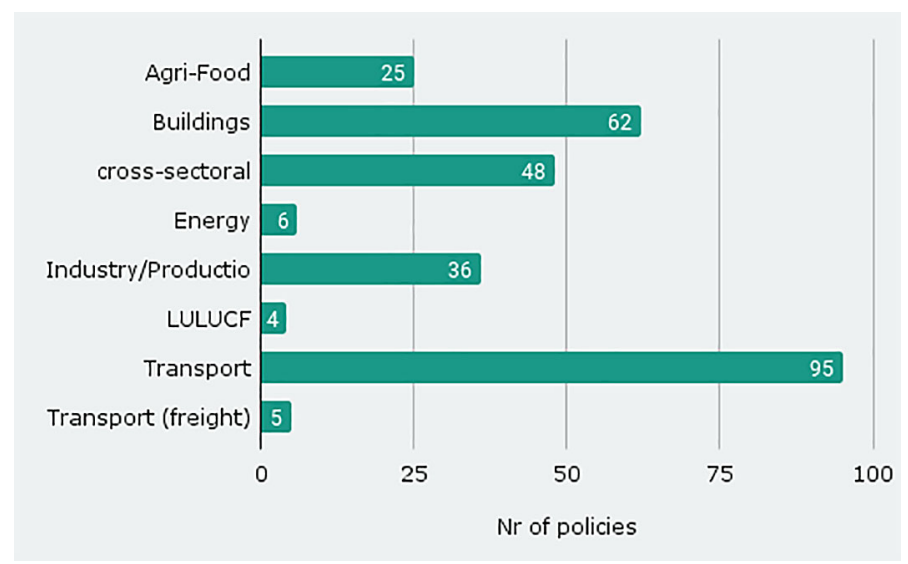

Figure 1. Number of policy instruments by sector.

${ }^{2} \mathrm{EnSu}$ - Research Group on energy sufficiency, https://energysufficiency.de/. 


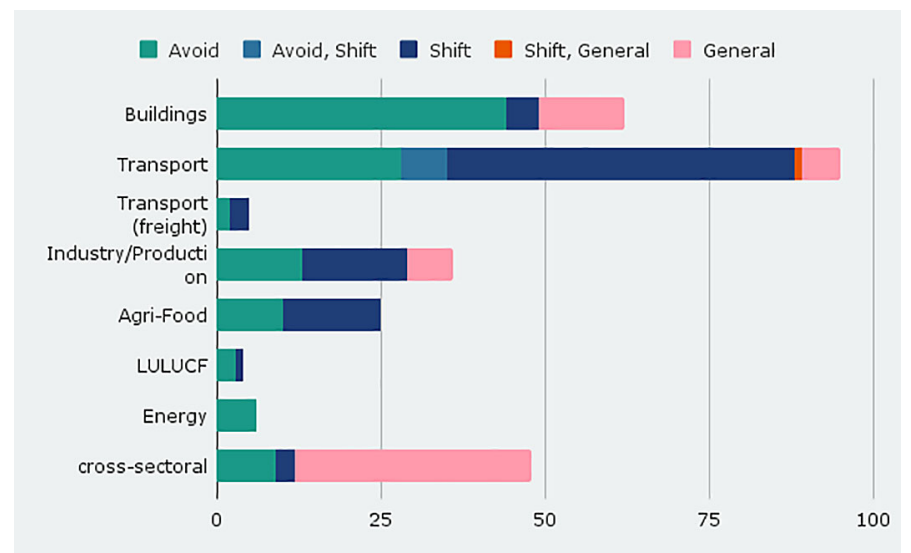

Figure 2. Number of policy instruments by sector and sufficiency type.

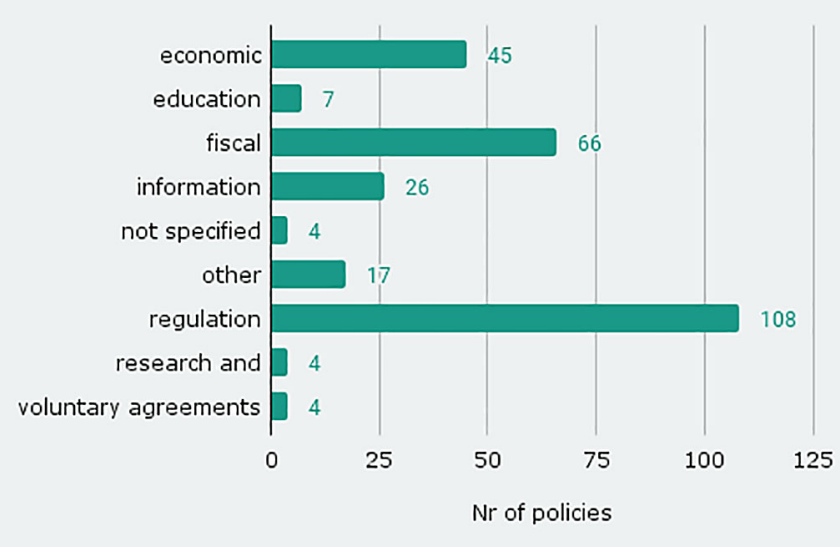

Figure 3. Number of policy instruments by instrument types.

leaving the responsibility to the individual, but a comprehensive mix of instruments. Sufficiency policy can thus be regarded as a policy field comparable to energy efficiency or renewable energies.

Figure 4 combines the information on sectors and instrument types. This highlights that the sufficiency policies proposed in the various sectors diverge in focus. In the building sector, fiscal (subsidy) instruments and regulations prevail while for the transport sector, the focus is more on fiscal/infrastructure policies, financial/tax incentives and regulation. For the industry/production sector, mostly regulatory instruments are included while cross-sectoral policy instruments are mostly financial incentives through taxation and subsidies as well as regulation. For the other sectors, fewer instruments of all types are included.

As a step towards model inclusion of sufficiency policies, we searched for specific target indicators that may eventually be included into models or, vice versa, that models may potentially give as outputs to quantify energy sufficiency. The database includes 79 unique indicators such as e.g. 'durability of products', 'car ownership rate', 'kg of exported meat' and ' $m^{2}$ living space/person' or ' $m^{2}$ unused living space'. For a complete list, see underlying data. These are indicators identified from the policy descriptions and may function as linking variables to sector and energy models and climate scenarios. $^{36}$

By summarizing the overall goals all identified sufficiency policy instruments, we identify 45 different policy goals (See underlying data). ${ }^{31}$ While most are quite sector-specific and concrete such as reduce motorized individual transport or efficient use of living space, some goals, especially the ones of cross-sectoral policy instruments, aim at more general goals of human well-being e.g. equal society,alternative welfare indicators and that would involve more fundamental changes of organizing principles of societies e.g. re-distribute and reduce paid work-time or promote commons. This shows that demand-side options are not only a means to mitigate climate change, but can also involve a more general strategy to reach socio-ecological goals and quality of life. 


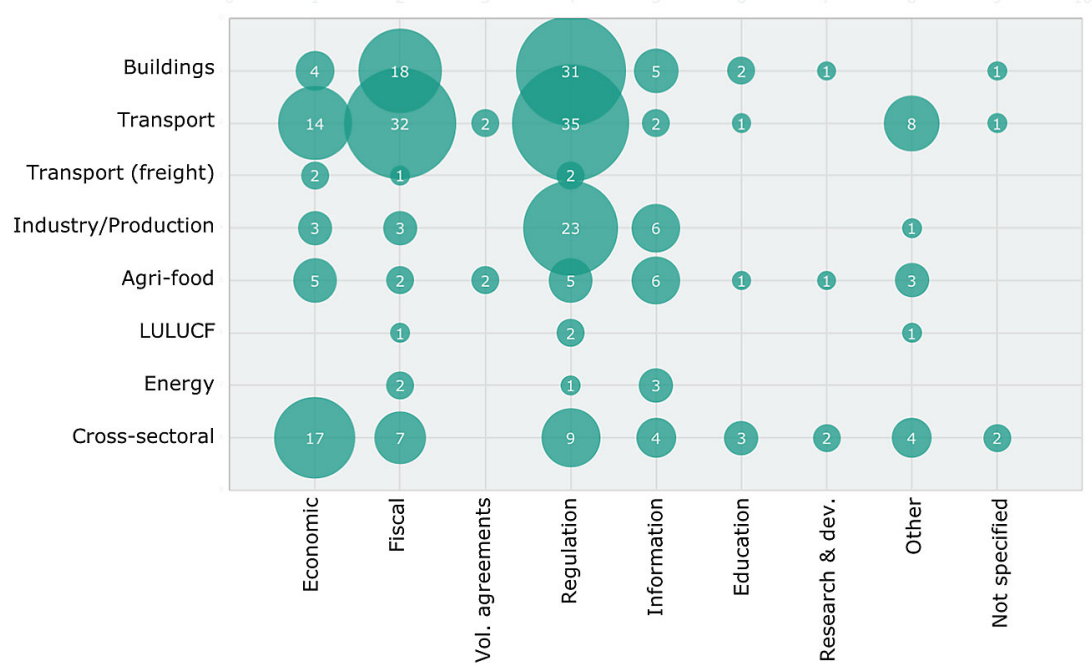

Figure 4. Number of policy instruments by sector and instrument type. Note: Bubble sizes indicate the number of instruments.

\section{Discussion}

Potentially, much like with energy efficiency and renewable energy policy, sufficiency policies are most effective and unfold all advantages, if not reduced to single measures but integrated into a consistent policy framework. We consider it still helpful to depict each policy instrument in detail in such a database on the one and provide the heterogeneity of sufficiency policy on the other side.

The database published along with this article is a first version and proof of concept. So far, we have a strong focus on European and German sources. We do not claim completeness and since it is a dynamic field, additional policy instruments will be added. We will also invite external persons to propose additional policies and plan to team up with other research stakeholders in the energy sufficiency field at German and EU level to investigate options for a successful continuation of the database including potential future (co-)hosts and possibilities for maintenance. Regarding its format, we plan to implement the sufficiency policy database as an online database.

Further planned developments of the database are the inclusion of quantitative effects (energy demand \& GHG-reduction potentials) of the policies. To this end, policy impact chains need to be investigated and the policy representation in models be expanded to include them in ex-ante assessments and scenario studies. ${ }^{37}$ Another possible addition is a prioritization regarding maturity, replicability and impact. ${ }^{38}$ To make more transparent which policies are actually reducing barriers for sufficiency, we will add the categorisation of barrier-reduction and sufficiency-supporting. Furthermore, we will add good practice and implementation examples to the entries of the database.

In the field of barriers, more research is required to identify current political barriers which might prevent the implementation of sufficiency. Due to the partly fundamental character of the changes some policy instruments of sufficiency represent, further research on economic effects, macroeconomic dynamics and culture is required which is beyond the scope of the database itself but is fundamental for a successful implementation of sufficiency policy.

\section{Conclusion}

Our energy sufficiency policy database of currently 281 policy instruments can serve as a basis to develop policy recommendations in the so far underrepresented field of sufficiency policy. Moreover, it provides a starting point for further research on sufficiency and climate change mitigation policies, especially for modelling and scenario studies. The identification of indicators is a first step to include sufficiency into modelling and be able to assess the effect of the different policy measures.

As the variety of different instrument types, goals and policy levels shows, sufficiency is a diverse policy field with multiple options of implementation and effect. The database encompasses specific instruments but also fundamental structural changes of societal organisation principles. Our interdisciplinary approach is helpful to cover the heterogeneity of sufficiency. The description on concrete information on sufficiency as policy, with goals, instruments and indicators as 
an interface to modelling can help to overcome existing barriers on sufficiency policy implementation. Making it more tangible can support its path to becoming a key strategy for energy policy.

\section{Data availability}

Underlying data Zenodo: Sufficiency Policy Database $\mathrm{DOI}^{31}$ : This project contains the following underlying data: Sufficiency Policy Database

Source data https://energysufficiency.de/policy-database/ (latest version of the sufficiency policy database)

Data are available under the terms of the Creative Commons Attribution 4.0 International (CC BY 4.0).

\section{Author contributions}

Benjamin Best: Conceptualization, Funding Acquisition, Investigation, Methodology, Project Administration, Writing Original Draft Preparation, Writing - Review \& Editing; Johannes Thema: Conceptualization, Formal Analysis, Investigation, Methodology, Visualization, Writing - Original Draft Preparation, Writing - Review \& Editing; Carina Zell-Ziegler: Conceptualization, Formal Analysis, Investigation, Methodology, Visualization, Writing - Original Draft Preparation, Writing - Review \& Editing; Frauke Wiese: Conceptualization, Funding Acquisition, Investigation, Methodology, Project Administration, Writing - Original Draft Preparation, Writing - Review \& Editing; Jonathan Barth: Resources; Stephan Breidenbach: Resources; Leonardo Nascimento: Resources, Writing - Review \& Editing; Henry Wilke: Resources

\section{Acknowledgements}

The authors would like to thank the members of their advisory boards for policy ideas and feedback. Great thanks to Diana Süsser and Bendix Vogel for technical advice. Thanks to the organizers and the participants of the session "Reaching our Targets - Making Europe fit for 55" of the EMP-E 2021 Conference.

1. Creutzig F, Niamir L, Bai X, et al.: Demand-side solutions to climate change mitigation consistent with high levels of well-being. Nat. Clim. Chang. 2021; 12: 36-46. Publisher Full Text

2. Zell-Ziegler C, Thema J, Best B, et al.: Enough? The role of sufficiency in European energy and climate plans. Energy Policy. 2021; 157: 112483. Publisher Full Text

3. Grunwald A: Wider die Privatisierung der Nachhaltigkeit Warum ökologisch korrekter Konsum die Umwelt nicht retten kann. GAIA-Ecological Perspectives for Science and Society. 2010; 19(3): 178-182. Publisher Full Text

4. Bilharz M, Fricke V, Schrader U: Wider die Bagatellisierung der Konsumentenverantwortung. GAIA - Ecological Perspectives for Science and Society. 2011; 20: 9-13. Publisher Full Text

5. Grunwald A: Statt Privatisierung: Politisierung der Nachhaltigkeit. GAIA - Ecological Perspectives for Science and Society. 2011; 20: 17-19. Publisher Full Text

6. Heidbrink L, Schmidt I, Ahaus B: Die Verantwortung des Konsumenten. Sozialwissenschaften 2011. 1st ed. Frankfurt am Main: Campus Verlag $\mathrm{GmbH} ; 2011$.

7. Toulouse E, Sahakian M, Lorek S, et al.: Energy sufficiency: how can research better help and inform policy-making?. 2019. Reference Source

8. Zell-Ziegler C, Förster H: Mit Suffizienz mehr Klimaschutz modellieren. Number 55/2018 in Texte. Umweltbundesamt, Dessau. 2018. Reference Source

9. Samadi S, Gröne M-C, Schneidewind U, et al.: Sufficiency in energy scenario studies: Taking the potential benefits of lifestyle changes into account. Technol. Forecast. Soc. Chang. 2017; 124 126-134.

Publisher Full Text
10. International Energy Agency (IEA) and International Renewable Energy Agency (IRENA): IEA Policies database. 2022. Reference Source

11. European Environment Agency (EEA): EEA database on climate change mitigation policies and measures in Europe. 2022 Reference Source

12. Dutch Research Institute For Transitions (DRIFT): Critical Turning Points Database. 2022. Reference Source

13. NewClimate Institute: Climate Policy Database. 2022 Reference Source

14. Agence de l'environnement et de la maîtrise de l'énergie (ADEME) and Partners of Odyssee-Mure: MURE database on energy efficiency measures' of ODYSSEE-MURE. 2022 Reference Source

15. Gynther L, Eichhammer W: Energy Sufficiency Indicators and Policies. Technical report. Helsinki: Motiva Oy \& Fraunhofer Institute for Systems and Innovation Research ISI; 2021. Reference Source

16. Institut für zukunftsfähige Ökonomien e.V: Sustainable Prosperity made in Europe. 2021. Reference Source

17. Breidenbach S, Bußmann-Welsch TM, Fischer L, et al:: Maßnahmen für ein 1,5-Grad-Gesetzespaket. Arbeitsstand: September 2021. Technical report. Hamburg: GermanZero e. V.; 2021. Reference Source

18. Association négaWatt: Scénario négaWatt 2017-2050 - Dossier de synthèse. Technical report. Valence: Fondation Charles Léopold Mayer pour le progrès de l'Homme; 2017. Reference Source

19. Bertoldi P: Are current policies promoting a change in behaviour, conservation and sufficiency? An analysis of existing policies and recommendations for new and effective policies. ECEEE; 2017. recommendations for
Refence Source 
Best Wagner O: Prepaid-Strom per Smartphone. Energiewirtschaftliche Tagesfragen. 2020; (11): 74-77. Reference Source

21. BürgerBegehren Klimaschutz e. V: Unsere Empfehlungen für die deutsche Klimapolitik. Technical report, Schöpflin Stiftung Open Society Foundations, GLS Treuhand, Postcode-LotterieStiftung, Berlin. September 2021. Reference Source

22. Dittrich F, Dünnebeil S, von Köppen A, et al.: Transformationsprozess zum treibhausgasneutralen und ressourcenschonenden Deutschland GreenSupreme. Number 05/2020 in Climate Change. Umweltbundesamt (UBA), Dessau. 2020. Reference Source

23. Faber J: Behavioural climate change mitigation options and their appropriate inclusion in quantitative longer term policy scenarios. 2012. Reference Source

24. Fuhrhop D: "Bauverbot” und Suffizienz im Stadtwandel. Adler F, Schachtschneider U, editors. Postwachstumspolitiken. oekom; pages 293-304.

25. Gota S, Huizenga C, Peet $\mathrm{K}$, et al.: Decarbonising transport to achieve Paris Agreement targets. Energ. Effic. February 2019; 12(2): 363-386. Publisher Full Text

26. Jackson T: Prosperity without Growth: Foundations for the Economy of Tomorrow. 2nd ed. London/New York: Routledge; 2016.

27. Matthias $V$, Bieser J, Mocanu $T$, et al.: Modelling road transport emissions in germany - current day situation and scenarios for 2040.87: 1-17

Publisher Full Text

28. Potočnik J, Spangenberg J, Alcott B, et al.: Sufficiency. Moving beyond the gospel of eco-efficiency. Technical report, Friends of the Earth Europe, Federal Ministry of the Environment, Nature Conservation, Building and Nuclear Safety and of the Federal Environment Agency of the Federal Republic of Germany, European Commission, Brussels. 2018.

Reference Source
29. Repenning J, Emele L, Blanck R, et al.: Klimaschutzszenario 2050-2. Endbericht. Technical report. Öko-Institut; Fraunhofer ISI; 2015. Reference Source

30. Scherhorn G: Die Welt als Allmende - Für ein gemeingütersensitives Wettbewerbsrecht. 2012.

31. Best B, Thema J, Zell-Ziegler C, et al.: Sufficiency policy database [data set]. in f1000research: Vol. energy systems modelling, (v 0.1) Publisher Full Text

32. UNFCCC: Review of the implementation of commitments and of other provisions of the Convention. UNFCCC guidelines on reporting and review. Bonn: 2000 Reference Source

33. Steg L, Tertoolen G: Sustainable transport policy: the contribution from behavioural scientists. Public Money Manag. 1999; 19(1): 63-69. Publisher Full Text

34. Marks G: Structural policy in the European Community Sbragia A, editor. Europolitics: Institutions and Policy Making in the 'New' European Community. Washington D.C.: The Brookings Institution; pages 191-224. 1992.

35. Pier Domenico Tortola: Clarifying multilevel governance. Eur. J Polit. Res. May 2017; 56(2): 234-250. Publisher Full Text

36. Wiese F, Thema J, Cordroch L: Strategies for climate neutrality Lessons from a meta-analysis of German energy scenarios. Renewable and Sustainable Energy Transition. December 2021; 2 100015. Publisher Full Text | Reference Source

37. Zell-Ziegler C, Thema J: Impact chains for energy sufficiency policies - a proposal for visualisation and possibilities for integration into energy modelling.TATuP; forthcoming.

38. Martin B, Pestiaux J, Schobbens $Q$, et al: A radical transformation of mobility in Europe: Exploring the decarbonisation of the transport sector by 2040.2020. Reference Source 


\section{Open Peer Review}

\section{Current Peer Review Status:}

\section{Version 1}

Reviewer Report 14 April 2022

https://doi.org/10.5256/f1000research.120251.r127903

(C) 2022 Schäfer $\mathbf{M}$ et al. This is an open access peer review report distributed under the terms of the Creative Commons Attribution License, which permits unrestricted use, distribution, and reproduction in any medium, provided the original work is properly cited.

\section{Mirko Schäfer \\ INATECH, University of Freiburg, Freiburg, Germany \\ Celia Burghardt \\ INATECH, University of Freiburg, Freiberg, Germany}

The authors present a database for sufficiency policies, including and categorising almost 300 policy instruments, with a focus on Germany and Europe.

Sufficiency measures are currently underrepresented in the discussion of transformation pathways towards a climate neutral energy system. In particular, this applies to energy system modelling for scenario development and analysis. Often the focus is on the technological transformation and advancement, without the consideration of demand-side solutions. Although recently an increased interest in such demand-side solutions can be observed, there is still a research gap in identifying, quantifiying and modelling sufficiency strategies and policies. The authors address this issue by presenting a database for energy sufficiency policies.

In the current form, the database already represents a valuable source of information about a large number of sufficiency policies, categorised in a very well structured way and linked to references. In this way, already in its present form, it can be seen as an important starting point and gateway for anyone interested in sufficiency policies. The audience already more familiar with such concepts might object to certain categorisation choices or seek additional information, but also for this purpose the database can be helpful as a seed and potential platform for discussion.

Nevertheless, in its current form, the database only represents a starting point for further research. This is clearly acknowledged by the authors in the article and here is not intended as an argument against the publication of this contribution. Very important next steps could be towards more quantification (parameter settings as an input for system modelling), impact chains as a guidance for sector-specific modelling, and the extension beyond Europe.

To allow further development, a clearer view on how the community can interact with and through the database should be developed. This should include both the ability for users to contribute to 
the database (facilitated by clear explanation and examples on the categorisation) and the possibility to provide feedback on the usefulness or shortcomings of the database. For this purpose, it might be an option to link the database to a (moderated) discussion forum.

With regard to the analysis of the already represented sufficiency policies, it would be interesting to discuss in more detail why certain types of instruments in certain sectors are dominant in the database. Is this due to limited options for other sectors/instruments, or can this be explained with a bias in the underlying research?

To conclude, we are confident that the database serves as a valuable source for the audience seeking a first introduction into sufficiency policies, as well as an important starting point for research towards a broader and deeper integration of sufficiency policies into energy system analysis and modelling.

Is the work clearly and accurately presented and does it cite the current literature? Yes

Is the study design appropriate and is the work technically sound? Yes

Are sufficient details of methods and analysis provided to allow replication by others? Yes

If applicable, is the statistical analysis and its interpretation appropriate? Not applicable

Are all the source data underlying the results available to ensure full reproducibility? Yes

Are the conclusions drawn adequately supported by the results? Yes

Competing Interests: These reviewers are part of a larger working group ("Integrated Energy Systems" of the project Energy Systems of the Future). One of the authors (Frauke Wiese) is also member of this working group.

Reviewer Expertise: Energy system analysis and modelling

We confirm that we have read this submission and believe that we have an appropriate level of expertise to confirm that it is of an acceptable scientific standard.

Author Response 30 Jun 2022

Benjamin Best

Dear Mirko, thank you for your review! It is very valuable to us for the next versions of our database. We thought about possible explanations why some instrument types are 
dominant in sectors. A possible reason is that price instruments are easiest to model, so that we need to consider a certain bias due to the methods of the underlying research. This will help to consider limitations when drawing conclusions from analysis of our database.

Competing Interests: No competing interests were disclosed.

Reviewer Report 24 March 2022

https://doi.org/10.5256/f1000research.120251.r125368

(C) 2022 Vita G. This is an open access peer review report distributed under the terms of the Creative Commons Attribution License, which permits unrestricted use, distribution, and reproduction in any medium, provided the original work is properly cited.

\section{Gibran Vita}

Environmental Sciences, Open University of the Netherlands, Heerlen, The Netherlands

The authors make a very good effort and praiseworthy initiative to try to bring sufficiency into more concrete policy terms and instruments. The database is a living document. As such, it cannot be currently judged as a finished product. It will change shape as it progresses.

Its current version does seem to over-rely or over-represent few sources and countries (Germany). In that case, I don't see it as a really comprehensive database. Too many countries and initiatives missing, even in Europe. It is however remarkable that with such a narrow range of sources you still find more than 100 policies. Maybe a full-blown European database would be massive, but highly desirable in my opinion.

One of the sources is "expert consultation" but no transparency on this as far as I could read. Maybe this was just meant to get an overview of current databases.

In its current form, it seems more like a summarized and user-friendly way to navigate a handful of reports. Which is still useful, especially since you translated German documents into English entries, but not really what the title and abstract seems to sell. I look forward for it to grow and become more diverse and comprehensive.

Concrete suggestions:

The database could benefit from consistency in reporting which countries the policies are present in. In some categories the countries are mentioned, in some others not, even when a given policy seems to only apply to Germany, for example. Would search by country be enabled?

Another interesting variable to include would be the broader policy landscape or directive where the particular policy or instrument stems from. EU directive, Paris agreement, SDGs, UN biodiversity, etc. As the purpose of the database is to understand how to promote sufficiency policy, it seems key to understand which kind of broader policy movements facilitated that particular industry. 
The base year would be relevant to mention.

You can abbreviate the Shift, Avoid, to save space and include other things.

The title of the database should probably include "Europe" in the title. Or even Germany. Whatever you think represents it best. The sector "LULUCF" (and maybe some food and agriculture) doesn't seem to fit the "energy" exclusive topic.

In that sense, I would think that an indication of which resource is mainly spared: energy, carbon, etc. Or if it's synergistic measure: land, water, energy, etc. I understand this would be much more work at this point as it would have been to consider it since the start.

Perhaps a more critical point: to make it more useful it would be helpful to have the "implementation challenges" or "complementary policies" to avoid loss of wellbeing or energy backfire. For example, ban of domestic flights might rise car demand if we don't have a massive train subsidy. Challenges of reducing meat would need more education on plant-based lifestyles or a ban on artificial chemicals of plant-based meat substitutes. We need to think from the policymaker viewpoint.

Would have been useful to breakdown the biggest categories: regulation, fiscal and economic into subcategories. For example "regulation: ban". All these are very broad. For example, if one is interested on looking at bans. The search bar could be used instead but not sure if it's working properly or if it's also looking in the reference document? For example, if I write "ban" I get some results but can't find the word "ban" in those entries.

What is the plan to make it grow and have a life of its own? There doesn't seem to be a way to submit entries. Most importantly, having experience in these kinds of projects I would not rely on the good will of people to submit entries.

I strongly suggest the authors to consider a massive crowd-sourcing experiment where you extend authorship to many many more researchers and practitioners who are on top of this topic, maybe in exchange for min 5-10 entries. There is no limit to how many authors a database or paper can have. Might be a worthwhile experiment.

Great initiative and wish you success,

Gibran Vita

Is the work clearly and accurately presented and does it cite the current literature? Yes

Is the study design appropriate and is the work technically sound?

Yes

Are sufficient details of methods and analysis provided to allow replication by others? Partly 
If applicable, is the statistical analysis and its interpretation appropriate?

Not applicable

Are all the source data underlying the results available to ensure full reproducibility? Yes

Are the conclusions drawn adequately supported by the results?

Yes

Competing Interests: No competing interests were disclosed.

Reviewer Expertise: Industrial Ecology

I confirm that I have read this submission and believe that I have an appropriate level of expertise to confirm that it is of an acceptable scientific standard.

Author Response 30 Jun 2022

\section{Benjamin Best}

Thank you for your valueable feedback. We will update our database and consider your feedback for the next version. Your review provides us with actionable guidance for the next steps.

Competing Interests: No competing interests were disclosed.

The benefits of publishing with F1000Research:

- Your article is published within days, with no editorial bias

- You can publish traditional articles, null/negative results, case reports, data notes and more

- The peer review process is transparent and collaborative

- Your article is indexed in PubMed after passing peer review

- Dedicated customer support at every stage

For pre-submission enquiries, contact research@f1000.com 